\title{
Sex-Dependent Developmental Change of Rat Liver Cytosolic Alcohol Dehydrogenase Activity
}

\author{
Saori HARADA, ${ }^{1}$ Kaoru TACHIYASHIKI ${ }^{1,2, *}$ and Kazuhiko IMAIZUMI ${ }^{1,2}$ \\ ${ }^{1}$ Joint Graduate School in Science of School Education, Hyogo University of \\ Teacher Education, Katou-gun, Hyogo 673-1494, Japan \\ ${ }^{2}$ Department of Living and Health Sciences, Joetsu University of \\ Education, Joetsu, Niigata 943-8512, Japan
}

(Received August 2, 1999)

\begin{abstract}
Summary Rat liver cytosolic alcohol dehydrogenase (ADH) is the principal enzyme which catalyzes the oxidation of ethanol. $\mathrm{ADH}$ activity is known to be significantly higher in females than in males. However, the precise mechanism of the sex-difference in ADH activity is uncertain. Recently, we have shown that the inhibitory action of androgen and the slight facilitatory actions of progestin and estrogen are involved in the mechanism of sex-difference in adult rat liver ADH activity. In the present study, we studied the difference of the postnatal developmental changes of ADH activity between males and females. ADH activity increased rapidly after birth up to about $12 \mathrm{~d}$ of age, and was not different in the two sexes. In female rats, $\mathrm{ADH}$ activity peaked at about $30 \mathrm{~d}$ of age and then increased gradually to plateau levels. However, the ADH activity of male rats fell markedly between 30 and $45 \mathrm{~d}$ old, and the reduced enzyme activity was observed until $104 \mathrm{~d}$ old. In conclusion, the ADH activity of male rats fell between 30 and $45 \mathrm{~d}$ after birth. At the ages over the turning point, the ADH activity was significantly lower in male than in female rats.
\end{abstract}

Key Words alcohol dehydrogenase, growth, sex hormones, hormonal regulation, rats

Alcohol dehydrogenase (ADH; alcohol: $\mathrm{NAD}^{+}$oxidoreductase, EC 1.1.1.1) is a dimeric zinc-metalloenzyme principally responsible for ethanol oxidation in mammals. Although the exact physiological role of $\mathrm{ADH}$ is still unknown, ADH catalyzes the reversible interconversion of a variety of alcohols and their corresponding aldehydes and ketones $(1,2)$. Further, ADH catalyzes the oxidation or the reduction of a variety of physiological endogenous steroidal and non-steroidal substrates in addition to ethanol $(1,2)$. Three major classes of ADH have been identified on the basis of their electrophoretic mobilities, kinetic properties, substrate specificities and tissue distribution $(1,3,4)$. The class I $\mathrm{ADH}$ enzyme is the most abundant in the liver and accounts for the majority (about 96\%) of total ADH activity in the liver $(1,4)$. The class I ADH enzyme is also known to be most sensitive to inhibition by an ADH inhibitor, pyrazole (2). In the rat liver, there is a single class I ADH, while in the livers of humans and other animals, there are multiple forms (1).

It is generally accepted that rat liver ADH activity is known to be significantly lower in males than in females (5-7). Recently, we showed that the inhibitory action of androgen such as testosterone and the slight facilitatory actions of progestin and estrogen are involved in the mechanism of sex-difference on ADH activity (5). These results suggest that modulation of liver class I ADH activity and ethanol metabolism in the liver

\footnotetext{
* To whom correspondence should be addressed.
}

is regulated by sex hormones in rats (5). However, there are few reports on the difference and the mechanism of developmental patterns of $\mathrm{ADH}$ activity between male and female rats $(8)$. Moreover, testosterone is wellknown to cause decreased liver ADH activity $(1,5)$. Therefore, a significant decrease in ADH activity in male rats may be induced when blood testosterone levels and/or testosterone receptors during puberty are to be elevated. The growth change of ADH activity of male rats may be associated with the secretion levels of blood testosterone. It is essential for the complete elucidation of the regulation of ethanol metabolism in the liver by sex hormones to systematically study the sex-dependent growth of rat liver ADH activity (5).

To further clarify the sex-difference of ADH activity, we studied the difference in the postnatal developmental pattern of liver $\mathrm{ADH}$ activity between male and female rats.

\section{Experimental}

Animals. Sprague-Dawley rats (ages: 1-104d) were used. Pregnant female rats of $14 \mathrm{~d}$ after gestation were purchased from CLEA Japan, Tokyo. Animals under the age of $21 \mathrm{~d}$ were obtained from pregnant female rats in our animal laboratory, and were accompanied by a mother. In all cases, the pups in each litter were six to eight of the same sex. Rats beyond the age of $45 \mathrm{~d}$ were obtained from CLEA Japan, Tokyo.

All animals were normally maintained at a temperature of $23-25^{\circ} \mathrm{C}$ and at a relative humidity of $50-60 \%$. 

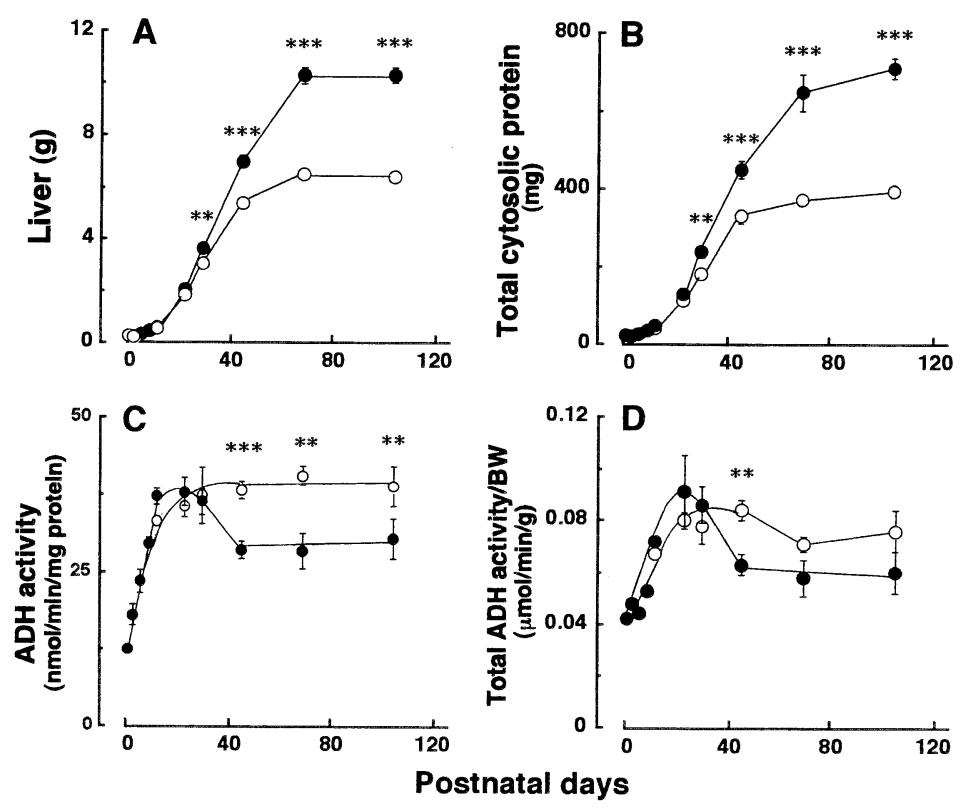

Fig. 1. Postnatal developmental changes of the liver weight (A), total liver cytosolic protein (B), liver cytosolic ADH activity (C) and total liver cytosolic ADH activity per unit BW (D).

$O$ : female rats and : male rats. Values: means \pm SE $\left(n=6-18\right.$ rats of each age). ${ }^{* *} p<0.01$ and ${ }^{* * *} p<0.001$ (vs. female rats, by Welch test).

Lighting was controlled automatically from 8:00 to 20:00 (9, 10). Animal diet (CE-2 type or CA-2 type, CLEA Japan, Tokyo) and once-boiled tap water were given to the rats ad libitum $(9,10)$. Animals were not starved before the start of the experiment. All rats were sacrificed by cervical dislocation (ages: 1-21 d) or decapitation (ages: 30-104 d) between 8:00 and 9:00 (5).

The present studies were carried out according to "Guiding Principles for the Care and Use of Animals in the Field of Physiological Sciences" of the Physiological Society of Japan (5).

Preparation of liver cytosolic fraction. The animals were sacrificed by cervical dislocation or decapitation, and the livers were quickly removed, weighed and perfused with ice-cold $0.9 \% \mathrm{NaCl}$ solution. As previously described (5), 10\% liver homogenates were prepared. Livers in rats under the age of $10 \mathrm{~d}$ were very small. Therefore, we prepared the homogenate using the livers from two or three rats. The homogenate was centrifuged at $7,000 \times g$ for $10 \mathrm{~min}$ at $5^{\circ} \mathrm{C}$. The pellet was discarded, and the supernatant was spun at 105,000 $\times$ $g$ for 60 min (Beckman XL-70, Palo Alto, California, USA) at $4^{\circ} \mathrm{C}(5)$. The liver cytosolic samples were prepared using the lobus hepatis sinistra lateralis from rats of ages of 20-104 d (5).

Assay of liver cytosolic ADH activity. As previously described $(5,10)$, ADH activities were assayed spectrophotometrically by following $\mathrm{NADH}$ formation at $340 \mathrm{~nm}$ at $38^{\circ} \mathrm{C}$. The enzyme activity was expressed as the amount of enzyme that produces $1 \mathrm{~nm} \mathrm{NADH} / \mathrm{min} /$ $\mathrm{mg}$ protein $(5,10)$. Liver cytosolic protein concentrations were determined by the method of Lowry et al. (11).

We determined the Michaelis constants $(\mathrm{Km})$ for ethanol and NAD $\left(\mathrm{pH} 9.0\right.$ and $\left.38^{\circ} \mathrm{C}\right)$. The $\mathrm{Km}$ values were obtained from the liver ADH activity of 1-104-dold male and female rats and were estimated as 0.73$0.85 \mathrm{~mm}$ for ethanol and 0.11-0.13 mu for NAD. These results agreed with other published data $(5,6)$.

Statistics. All data were expressed as means \pm SE. Welch-test was used to test for statistically significant differences. The differences were considered significant when $p$ was $<0.05$.

\section{Results}

Developmental change of liver weight and total liver cytosolic protein. As shown in Fig. 1, the liver weight (A) and total liver cytosolic protein (B) increased sigmoidally with age and were significantly higher in male than in female rats beyond the age of $30 \mathrm{~d}$. Similar sexdependent developmental patterns were observed in body weights (data are not shown). However, the developmental patterns of the liver weight per unit body weight and total liver cytosolic protein per unit body weight were sex independent (data are not shown).

The sex-difference of the developmental change of liver cytosolic ADH activity. Figure 1 shows the developmental changes of liver cytosolic ADH activity $(\mathrm{C})$ and total liver cytosolic ADH activity per unit body weight (D) in male and female rats. As shown in Fig. 1C, liver cytosolic ADH activity increased rapidly after birth to the age of $12 \mathrm{~d}$ in both sexes, and the developmental patterns of ADH activity were similar for both sexes from 1 to $30 \mathrm{~d}$ old. In female rats, ADH activity increased gradually with age, and reached a peak at the age of $69 \mathrm{~d}$. However, in male rats, ADH activity decreased markedly at the ages of 30 to $45 \mathrm{~d}$. Therefore, the ADH activity of female rats was 1.34 times $(p<0.001)$ significantly higher than that of male rats at the age of $45 \mathrm{~d}$. This prominent sex-difference in ADH activity was ob- 
served at ages of 69 and 104 d (Fig. 1C). Similar results were also observed in the total liver cytosolic ADH activity per unit body weight, as shown in Fig. 1D.

\section{Discussion}

The purpose of the present study was to elucidate the difference of the developmental pattern of liver cytosolic $\mathrm{ADH}$ activity between male and female rats. The present results clearly showed that the rat liver cytosolic $\mathrm{ADH}$ activity increased sex independently from ages of 1-30 d, but enzyme activity showed sex-dependent patterns from the ages of 45-104 d, and was significantly lower in the males as compared to the females (Fig. 1C).

As shown in Fig. 1C, a sex-difference in ADH activity was not seen before the age of $30 \mathrm{~d}$, and was not complete until the age of $45 \mathrm{~d}$. These ages form a period that matches that of puberty and maturation of the pituitary gland (12). Resko et al. (13) reported that plasma testosterone levels in male rats were 4.3-6.4 times $(0.64 \mathrm{ng} / \mathrm{mL}), 7.3-10.0$ times $(1.10 \mathrm{ng} / \mathrm{mL})$ and $13.6-$ 20.4 times $(2.04 \mathrm{ng} / \mathrm{mL})$ higher at the ages of 40,60 and $90 \mathrm{~d}$, respectively, than values $(0.10-0.15 \mathrm{ng} / \mathrm{mL})$ between the ages of $10-30 \mathrm{~d}$. These data clearly show that the developmental pattern of ADH activity in the male rat is opposite of the direction of the plasma testosterone level. The age range of the turning point was 30-45 d (Fig. 1C).

Our previous studies $(5,14)$ have shown that testosterone is responsible for the decrease in $\mathrm{ADH}$ activity of adult male rats, and the decreasing action of this sexsteroid hormone on enzyme activity is not mediated by direct interaction between $\mathrm{ADH}$ molecules and the steroid (5). Further, we also pointed out that the transcriptional activation of a rat class I ADH gene by hormone treatment must be considered a possible mechanism for the sex-difference of liver ADH activity in rats (5). As already published $(1,2,5,15)$, the ADH gene is hormonally regulated in rat liver, and the expression of rat liver class I ADH gene is regulated by several hormones $(1,3,5)$.

On the other hand, androgens are known to affect pituitary secretion, and the hypothalamo-pituitary system may be the androgen-sensitive organ in question $(1,12)$. This possibility may be supported by the finding that hypophysectomized male animals are unable to respond to androgen in the adult period (1). Further, it has long been known that androgens are involved in the regulation of steroid metabolism; castration increased the activity of the steroid $5 \alpha$-reductase, whereas testosterone treatment reduced the activity back to the normal male level (16). Such sex differences in the hepatic metabolism due to drugs have been shown for ethylmorphine, aniline, p-nitroanisol, lidocaine and imipramine, as well as for steroid hormones (16). These findings are in line with the results of androgen-induced changes in liver ADH activity, as already described $(5,14)$. The androgen dependency of a number of steroid-metabolizing enzymes is obviously not applicable to all sex-dependent enzymes in the liver. However, at least three groups of enzymes can be distin- guished on the basis of their androgen dependence: Group I is entirely dependent, group II is partially dependent, and group III is independent (15). Therefore, the decreased action of androgens such as testosterone on rat liver cytosolic ADH activity $(1-3,5,14)$ may be assigned to group I or group II.

It is generally accepted that $\mathrm{ADH}$ is a cytosolic enzyme with a relatively long half-life of about $4 \mathrm{~d}$, and receptors for gonadal steroids are known to be contained in the rat liver (16). Moreover, the $\mathrm{Km}$ values of $\mathrm{ADH}$ for ethanol and $\mathrm{NAD}^{+}$were not affected at the ages of 1$104 \mathrm{~d}$ when examined in the present study (data not shown). ADH activity is known to be regulated by more than one hormone, and the effect of the administration of one hormone on enzyme activity may depend on its interaction with hormones (5, 7). Among the bestknown interactions are those between androgens and growth hormones $(\mathrm{GH})(17,18)$. For instance, pituitary $\mathrm{GH}$ levels are higher in the male rat than in the female rat; castration of the male rat decreases $\mathrm{GH}$ to the level in the female, and the administration of testosterone to the female rat increases the GH level. Further, the effect of $\mathrm{GH}$ in decreasing ethylmorphine dimethylation in normal male rats, but not in normal female rats, appears to be partly due to an effect of GH antagonizing the stimulating action of testosterone on microsomal enzymes $(1,5,17)$. Testosterone is thus known to enhance maximum $\mathrm{GH}$ levels in humans after various stimuli such as hypoglycemia (1). As reported in our previous paper (5), because testosterone and female hormones such as $\beta$-estradiol and progesterone appear to have opposing actions on liver $\mathrm{ADH}$ activity, the relative ratio of estradiol to testosterone may be an important determinant of the rate of ethanol metabolism (1, $17,18)$.

Further studies are required using female rats to more fully assess the regulation of liver $\mathrm{ADH}$ activity and the metabolism of ethanol in each developmental stage $(5,17)$.

In conclusion, liver cytosolic ADH activity in male rats falls between 30 and $45 \mathrm{~d}$ after birth. In ages over the turning points, $\mathrm{ADH}$ activity is significantly lower in male rats as compared to female rats.

\section{Acknowledgements}

We thank Prof. Mitsuko Okada (Naruto University of Education, and Joint Graduate School in Science of School Education, Hyogo University of Teacher Education) for her useful discussion and suggestions throughout this work.

\section{REFERENCES}

1) Mezey E, Potter JJ, Yang VW. 1993. Hormonal regulation of the rat class I alcohol dehydrogenase gene. Alcohol Alcoholism Suppl 2: 57-62.

2) Cortese JF, Majewski JL, Crabb DW, Edenberg HJ, Yang VW. 1994. Characterization of $5^{\prime}$-flanking sequence of rat class I alcohol dehydrogenase gene. J Biol Chem 269: 21898-21906.

3) Potter JJ, Mezey E, Cornelius P, Crabb DW, Yang VW. 1992. The first 22 base pairs of the proximal promoter 
of the rat class I alcohol dehydrogenase gene is bipartite and interacts with multiple DNA-binding proteins. Arch Biochem Biophys 295: 360-368.

4) Canto MF, Oliva MM, Potter JJ, Mezey E, Yang VW. 1992. Enhancer-site downstream binding protein activity is enriched in rat tissues that express the class I alcohol dehydrogenase gene. Biochem Biophys Res Commun 188: 684-689.

5) Harada S, Tachiyashiki K, Imaizumi K. 1998. Effect of sex hormones on rat liver cytosolic alcohol dehydrogenase activity. J Nutr Sci Vitaminol 44: 625-639.

6) Tachiyashiki K, Imaizumi K, Ogita Z-I. 1987. Alcohol dehydrogenase activity in the rat livers of different portion, sex and age. Nippon Eiyo Shokuryou Gakkaishi (J Jpn Soc Nutr Food Sci) 40: 207-212.

7) Crabb DW. 1987. Studies on the hormonal regulation of rat liver alcohol dehydrogenase. In: Enzymology and Molecular Biology of Carbonyl Metabolism (Weiner H, Flynn TG, eds), p 245-258, Alan R Liss, New York.

8) Lad PJ, Shoemaker WJ, Leffert HL. 1984. Developmental changes in rat liver alcohol dehydrogenase. Dev Biol 105: 526-529.

9) Tachiyashiki K, Imaizumi K. 1992. Lowering and delaying actions of bovine bile on plasma ethanol levels in rats. J Nutr Sci Vitaminol 38: 69-82.

10) Tachiyashiki K, Imaizumi K. 1993. Effects of vegetable oils and $\mathrm{C}_{18}$-unsaturated fatty acids on plasma ethanol levels and gastric emptying in ethanol-administered rats. J Nutr Sci Vitaminol 39: 163-176.
11) Lowry OH, Rosebrough NJ, Farr AL, Randall RJ. 1951 Protein measurement with the Folin phenol reagent. J Biol Chem 193: 265-275.

12) Ketelslegers JM, Hetzel WD, Sherins RJ, Catt KJ. 1978. Developmental changes in testicular gonadotropin receptors: plasma gonadotropins and plasma testosterone in the rat. Endocrinol 103: 212-222.

13) Resko JA, Feder HH, Goy RW. 1968. Androgen concentration in plasma and testis of developing rats. J Endocr 40: $485-491$.

14) Tachiyashiki K, Imaizumi K. 1995. Effects of orchiectomy or ovariectomy and testosterone administration on rat liver cytosolic alcohol dehydrogenase. Jpn J Physiol 45 (Suppl.1): S252.

15) Gustafsson J-A,, Mode A, Norstedt G, Skett P. 1983. Sex steroid induced changes in hepatic enzymes. Ann Rev Physiol 45: 51-60.

16) Crow KE, Hardman MJ. 1989. Regulation of rates of ethanol metabolism. In: Human Metabolism of Alcohol (Crow KE, Batt RD, eds), Vol II, p 3-16. CRC Press, Boca Raton, Florida.

17) Cicero TJ, Newman KS, Schmoeker PF, Meyer ER. 1982. Role of testosterone in ethanol- and morphine-induced increases in the alcohol dehydrogenase-dependent metabolism of ethanol in the male rat. J Pharmacol Exp Ther 222: 20-28.

18) Crabb DW, Bosron WF, Li T-K. 1987. Ethanol metabolism. Pharmac Ther 34: 59-73. 